\title{
1 Micro-Scale Isotopic Analysis of Ice Facies Frozen from Supercooled \\ 2 Water
}

3

4 Connor J. Shiggins ${ }^{\mathrm{a} 1 *}$, Matthew R. P. Harris ${ }^{\mathrm{a}}$, Peter G. Knight ${ }^{\mathrm{a}^{*}}$,

5 Christopher J. Fogwill ${ }^{\mathrm{a}}$.

$6{ }^{a}$ School of Geography, Geology and the Environment, Keele University, Staffordshire,

7 ST5 5BG, United Kingdom.

8 *Correspondence to: Connor Shiggins (Connor.Shiggins@liverpool.ac.uk).

9 Connor J. Shiggins: PhD student at University of Liverpool. Twitter handle:

$10 @$ glacialicon

11 Matthew R. P. Harris: PhD student at Keele University. Twitter handle:

12 @Organic_Matters

13 Peter G. Knight: Reader in Geography, Head of Geography Programmes and Physical

14 Geography Course Director at Keele University. Twitter handle: @ PKGeog

15 Christopher J. Fogwill: Professor of Glaciology and Palaeoclimatology and Head of

16 School at Keele University.

17 Word Count: 4,483

18

${ }^{1}$ Connor Shiggins has changed affiliation during the peer review process from Keele University to the University of Liverpool. The new address is: Department of Geography and Planning, School of Environmental Sciences, University of Liverpool, Liverpool, L69 7ZT, United Kingdom. 


\section{Micro-Scale Isotopic Analysis of Ice Facies Frozen from Supercooled \\ 20 Water}

ABSTRACT. Subglacial glaciohydraulic supercooling can form basal ice and affect glacier dynamics, sediment transfer and geomorphology. Whilst isotopic analysis $\left(\delta^{18} \mathrm{O}-\delta \mathrm{D}\right)$ of basal ice has demonstrated the significance of supercooling, questions remain as to what extent the identification of supercooling depends on sampling resolution. We conducted laboratory experiments in which ice was frozen from supercooled water and sampled at a micro-scale (1.5 millilitre) to identify highly localised variations in isotopic compositions that might be lost in bulk-scale sampling. Three distinctive ice facies produced by the freezing process demonstrated diagnostic isotopic signatures that were distinguished when the facies were sampled independently. However, their respective isotopic signatures were lost when bulk-scale sampling combined the two facies, demonstrating the requirement of micro-scale sampling when identifying supercooling in basal ice facies. These findings indicate that sampling for isotopic compositions of ice facies frozen from supercooled water should be conducted at a scale that prevents the amalgamation of different facies to highlight a detailed isotopic signature. We conclude that micro-scale sampling is imperative to understanding and quantifying this subglacial process.

Keywords: supercooling, isotopes, sample size, freezing slopes. 


\subsection{Introduction}

45 Glaciohydraulic supercooling occurs when basal water at, or below the pressure melting

46 point ascends from a subglacial overdeepening and the water temperature rises quicker

47 than the water which is heated by viscous dissipation (Alley et al. 1998; Lawson et al. 1998). Where it occurs, supercooling can lead to the accretion of ice at the base of glaciers even where the basal thermal regime is temperate, and provides a mechanism

50 for the creation of debris-rich basal ice in those temperate settings. Supercooling was

51 found to be the primary formational process of stratified basal ice at the Matanuska Glacier, Alaska (Alley et al. 1998; Lawson et al. 1998; Evenson et al. 1999; Ensminger et al. 2001; Larson et al. 2010; Larson et al. 2016). At other temperate glaciers which could support supercooling, the Matanuska-type model has been shown to be less efficient with regards to basal ice formation elsewhere (Spedding and Evans, 2002; Swift et al. 2006; Cook et al. 2007; 2010; Swift et al. 2018). For example, Cook et al. (2010) determined supercooling only formed $42 \%$ of the stratified basal ice facies at Svínafellsjökull, Iceland.

Ice formed from supercooled water is known to be isotopically $\left(\delta^{18} \mathrm{O}-\delta \mathrm{D}\right)$ lighter

60 relative to the parent water, but the extent to which this occurs is unknown (Lawson et

61 al. 1998; Ensminger et al. 2001; Cook et al. 2010; Larson et al. 2010). Cook et al.

62 (2010) found at Svínafellsjökull that the isotopic composition of anchor ice frozen from supercooled water was lighter by $\sim 2.4 \%$ in $\delta^{18} \mathrm{O}$ and $15.2 \%$ in $\delta \mathrm{D}$ relative to the

64 subglacial upwelling. Larson et al. (2010) concluded that supercooling at Vatnajökull 65 and Öræfajökull, Iceland was the primary formational process for the stratified basal ice 66 facies because it was lighter by $\sim 2.4 \%$ in $\delta^{18} \mathrm{O}$ and $12 \%$ in $\delta \mathrm{D}$ relative to the vent water. Thus, whilst we understand the isotopically light nature of stratified basal ice 
formed from supercooling, a lack of detailed knowledge remains surrounding the specific mechanisms and levels to which this occurs.

Methods used to quantify supercooling consist of visual, sedimentological, stable isotope and radionuclide analysis (e.g. Alley et al. 1998; Lawson et al. 1998; Evenson et al. 1999; Titus et al. 1999; Ensminger et al. 2001; Roberts et al. 2002; Spedding and Evans. 2002; Swift et al. 2006; Cook et al. 2007; 2010; Larson et al. 2010; Cook et al. 2011; Swift et al. 2018). Here, we focus on the importance of sample scale for stable water isotope analysis of ice facies frozen from supercooled water. Water isotope analysis has frequently been used as a quantification method when evaluating the significance of glaciohydraulic supercooling (e.g. Lawson et al. 1998; Titus et al. 1999; Ensminger et al. 2001; Swift et al. 2006; Cook et al. 2010; Larson et al. 2010). Sample sizes of basal ice formed from supercooling collected at glaciers for isotopic analysis range from 25-300 mL (Titus et al. 1999; Ensminger et al. 2001; Swift et al. 2006; Cook et al. 2010; Larson et al. 2010). However, due to their large sizes, these basal ice samples could contain ice facies formed from multiple alternative processes. This amalgamation of different ice facies could dilute the isotopic fingerprint of supercooling, potentially leading to an inaccurate diagnosis of basal ice formation. This study develops on comments from Cook et al. (2010) suggesting the scale in which basal ice samples are collected will be important as bulk-scale sampling could homogenise the isotopic signatures of formational processes.

$$
\text { Basal ice investigations separate from supercooling have also considered their }
$$
sample sizes. Hubbard and Sharp (1993) illustrated if the basal ice layer is sampled with a cylindrical sampler that has a diameter of $2 \mathrm{~cm}$, it could incorporate several layers of laminated facies, instead of a single layer of ice. Souchez and De Groote (1985) sampled basal ice samples at the base of Grubengletscher that were placed in $30 \mathrm{~mL}$ 
93 glass bottles. Souchez et al. (1998) revised a sampling strategy developed by Souchez

94 and DeGroote (1985), collecting samples at a resolution of $1 \mathrm{~mL}$ instead of $30 \mathrm{~mL}$ from

95 five Arctic glaciers. A fractional melting experiment was applied from Russell Glacier

96 and demonstrated the lack of fractionation by sampling $25 \mathrm{~mL}$ of melt water. The

97 clustering of samples on co-isotopic plots $\left(\delta^{18} \mathrm{O}-\delta \mathrm{D}\right)$ suggested there was no

98 fractionation during basal ice formation by regelation, or the scale of the sample had

99 homogenised the isotopic compositions (Souchez et al. 1988).

100 This study takes a laboratory-based approach to investigate whether field studies

101 of basal ice evaluating glaciohydraulic supercooling should consider a micro-scale

102 approach to sample size collection at glaciers. Replicating supercooling conditions

103 under laboratory conditions has been performed in three studies to date (Knight PG and

104 Knight DA, 2005; 2006; Cook et al. 2012). The overarching similarity found by the

105 studies was a distinct 'herringbone' crystal structure associated with supercooling

106 (Figure 1). This diagnostic crystal structure forms as a result of multi-directional ice

107 growth during freezing from supercooled water (Knight PG and Knight DA, 2005).

108 Thus, ice frozen from supercooled water will henceforth be referred to as 'herringbone

109 ice'. In order to determine whether bulk-scale sampling of ice frozen from supercooled

110 water yields the same isotopic composition as a micro-scale sampling approach, four

111 laboratory experiments were performed in a closed-system.

112 [Figure 1 near here]

\section{$113 \quad 2.0$ Methodology}

114 We sampled and melted ice frozen from supercooled water on a $1.5 \mathrm{~mL}$ scale to identify

115 any micro-scale isotopic differences in basal ice facies. Our aim was to determine

116 whether bulk-scale sampling resolves the same isotopic composition for the ice facies

117 frozen from supercooled water as the micro-scale sampling technique. Four laboratory 
118 experiments were conducted, with the sampled ice isotopically and statistically

119 analysed.

\section{$120 \quad 2.1$ Replicating Supercooling Conditions}

121 We followed previous methodologies which have replicated supercooling conditions

122 (Knight PG and Knight DA 2005, 2006; Cook et al. 2012), where a small recirculating

123 pump (flow-rate 1400 litres per hour) was clamped to the side of an open, plastic

124 container $(16 \times 36 \times 27 \mathrm{~cm})$ half filled with tap water to a depth of $8 \mathrm{~cm}$ in a cold

125 laboratory at $-12{ }^{\circ} \mathrm{C}$. The tap water had a temperature of $11{ }^{\circ} \mathrm{C}$ at the beginning of each

126 experiment before being placed in the cold laboratory. This setup stimulated

127 supercooling, keeping the water turbulent and allowing it to drop below $0{ }^{\circ} \mathrm{C}$ without

128 freezing. The pump was switched on and the experiment was left for five days. On the

129 fifth day, the pump was switched off to allow the remaining supercooled water to freeze

130 (Figure 2). After the seventh day, the ice block was removed from the container and

131 separated into its respective facies. The experiment was conducted four times across a

132 four-week period, accumulating 84 samples in total. 28 samples of each facies (clear,

133 herringbone and mixed) were sampled and analysed (Figure 3).

134 [Figure 2 near here]

135 [Figure 3 near here]

\subsection{Micro-Scale Sampling}

137 We applied a biased sampling strategy where the facies were sampled based on their

138 crystal structure. Once the ice types had been categorised into their facies, they were

139 carefully cut by a bandsaw to allow for micro-scale sampling. The samples were placed

140 on the bandsaw in the cold laboratory at $-12{ }^{\circ} \mathrm{C}$ and were pushed through the blade to 
141 create the thin sections in preparation for melting. The facies were visually identified

142 and separated precisely using the bandsaw, ensuring that the 'supercooled' sample only

143 contained the herringbone crystal structure. The mixed ice facies was sampled to

144 combine both the herringbone and clear ice, in order to determine whether this

145 amalgamation of facies would homogenise the isotopic composition of the herringbone

146 ice. After thin-sectioning, samples were immediately placed into sealed plastic

147 centrifuge tubes and moved to a room with a temperature of $15^{\circ} \mathrm{C}$ to allow the samples

148 to melt, ensuring no pre-melting.

\section{$149 \quad 2.3$ Isotopic Analysis}

150 The 84 samples from the four experiments were placed in vials and analysed in the

151 Keele University ICELAB with a Los Gatos Research (LGR) Triple Isotope Water

152 Analyser-DLT-EP, model 912-0032. The samples were measured at a precision of \pm 0.4

153 for $\delta \mathrm{D}$ and \pm 0.1 for $\delta^{18} \mathrm{O}$. Samples were interleaved such that a manufacturer standard

154 was measured every ten samples. After being measured, sample data was exported to

155 LGR's post-processing software to calibrate the measured samples against the included

156 LGR-supplied standards. We included standards that covered the isotopic range of the

157 measurements taken. The standards used, and their specifications are as follows:

$158 \longrightarrow$ LGR2C: $\delta \mathrm{D}=-123.7 \pm 0.5 \%$ vs VSMOW: $\delta^{18} \mathrm{O}=-16.24 \pm 0.15 \%$ vs VSMOW

159 LGR3C: $\delta \mathrm{D}=-97.3 \pm 0.5 \%$ vs VSMOW: $\delta^{18} \mathrm{O}=-13.39 \pm 0.15 \%$ vs VSMOW

160 LGR4C: $\delta \mathrm{D}=-51.6 \pm 0.5 \%$ vs VSMOW: $\delta^{18} \mathrm{O}=-7.94 \pm 0.15 \%$ vs VSMOW

162 Regression slopes between $\delta^{18} \mathrm{O}$ and $\delta \mathrm{D}$ (known as 'freezing slopes') can give insights

163 into refrozen water and water sources incorporated in the system and the associated 
164 fractionation. For example, depending on the gradient of a freezing slope, it can be

165 determined whether the input of water into a system has a similar isotopic composition

166 as the initial reservoir. Consequently, freezing slopes can be used as a method of

167 determining basal ice formation. Hypothetically, if a basal ice facies formed from an

168 initial water which had a slope of 6.7, and a second facies formed from a different water

169 source with a slope of 7.5, it indicates that these two facies formed from distinctly

170 different water sources because of the different slopes. However, if both facies yielded

171 an identical freezing slope of 6.7, it would suggest that the facies formed from the same

172 initial water and process.

173 As we conducted stable isotope analysis in a closed-system, the freezing slope

174 model determined by Jouzel and Souchez (1982) was utilised (Equation 1). This was

175 achieved by using the isotopic composition of the initial reservoir to determine the

176 gradient of our freezing slopes.

177

178

179

180

181

182

183

185

186

187

$$
\begin{aligned}
S & =[(\alpha-1) /(\beta-1)] \\
& \times\left[(1000+\delta \mathrm{D}) /\left(1000+\delta^{18} \mathrm{O}\right)\right]
\end{aligned}
$$

Where $S$ is the gradient of the freezing slope, $\alpha$ and $\beta$ are the equilibrium fractionation coefficients for deuterium and ${ }^{18} \mathrm{O}$ respectively (Jouzel and Souchez, 1982). We chose values for our equilibrium coefficients from Lehmann and Siegenthaler (1991), who conducted high precision measurements of the isotopic fractionation of ice grown on a cooling plate from an agitated water mass. They calculated that ' $\alpha$ ' had a value of 1.0212 and ' $\beta$ ' had a value of 1.00291 . The closed-system models were applied to the experiments to determine whether the models would predict the freezing slopes.

Freezing slopes will have a shallower gradient than the Global Meteoric Water Line (GMWL) which has a gradient of 8 on a $\delta \mathrm{D}-\delta^{18} \mathrm{O}$ co-isotopic plot. The GMWL is used 
189 (LMWL), because tap water was used as the source.

\section{$190 \quad 3.0$ Results}

\section{$191 \quad 3.1$ Experimental Observations}

192 Three facies froze in the four isolated experiments:

- Facies 1) Clear ice (frozen at $0{ }^{\circ} \mathrm{C}$ )

- Facies 2) Herringbone ice (artefact of supercooled water: frozen below $0{ }^{\circ} \mathrm{C}$ )

- Facies 3) Mixed ice (containing the herringbone and clear crystal structures)

196 The mixed ice facies contained both the herringbone and clear facies. It was treated as a

197 proxy for the bulk-scale sampling utilised in previous research, as it contained more

198 than one ice type. The herringbone ice has been suggested to be indicative of closed-

199 system supercooling freezing under laboratory conditions (Knight PG and Knight DA

200 2005, 2006; Cook et al. 2012). The herringbone facies formed at the lowermost section

201 of the container as this layer was nearest to the recirculating pump where the turbulence

202 was at its strongest, preventing freezing. The thickest layer was the mixed ice as it

203 contained two crystal structures (clear and herringbone) in the middle section of the

204 container. The clear facies froze as a relatively thin layer above the boundary of the

205 mixed facies because the turbulence had minimal impact at the uppermost layer of the 206 container.

\subsection{Isotopic Analysis}

208 Co-isotopic diagrams were constructed to highlight isotopic differences in the documented facies (Figure 4). The facies mean isotopic values, freezing slopes and

210 adjusted $R^{2}$ coefficients can be seen in table 1 . We report the adjusted $R^{2}$ values to show 
211 goodness of fit for the freezing slopes. The lowest adjusted $\mathrm{R}^{2}$ value is 0.93 for

212 experiment 3, indicating a strong agreement between the freezing slopes and the

213 measured isotopic values for all four experiments. The clear facies was the isotopically

214 lightest facies relative to the initial reservoir. The clear facies in experiment 1 was

215 lighter by $-12.4 \%$ in $\delta \mathrm{D}$ and $-1.8 \%$ in $\delta^{18} \mathrm{O}$ relative to the parent water. The mixed

216 facies was isotopically heavier than the initial water, e.g. $-12 \%$ in $\delta \mathrm{D}$ and $-1.6 \%$ in $\delta^{18} \mathrm{O}$

217 in experiment 1 . The herringbone facies was the isotopically heaviest facies compared

218 to the initial water, e.g. heavier by $-32 \%$ in $\delta \mathrm{D}$ and $-4.5 \%$ in $\delta^{18} \mathrm{O}$ in experiment 1 . This

219 trend continued throughout the remaining three experiments, with the clear ice being the

220 isotopically lightest, the mixed facies being heavier, and the herringbone ice being the

221 heaviest. The clear facies isotopic compositions ranged by $-14 \%$ for $\delta \mathrm{D}$ and $-2.5 \%$ for

$222 \delta^{18} \mathrm{O}$ across the four experiments. The mixed ice varied by $-13.7 \%_{0}$ in $\delta \mathrm{D}$ and $-2.3 \%$ in

$223 \delta^{18} \mathrm{O}$ and the herringbone facies had an isotopic range of $-22 \%$ for $\delta \mathrm{D}$ and $-3.8 \%$ for

$224 \delta^{18} \mathrm{O}$ across the four experiments. The parent water isotopically varied by $-0.4 \%$ in $\delta \mathrm{D}$

225 and $-1.6 \%$ in $\delta^{18} \mathrm{O}$.

226 [Figure 4 near here]

227 [Table 1 near here]

These variations in the $\delta^{18} \mathrm{O}$ compositions resulted in experiments 3 and 4 parent waters not plotting directly on the GMWL, suggesting the water had been modified isotopically from its meteoric source. Variations in parent water are important as they

231 can result in an ice facies having a heavy or light isotopic composition, having

232 implications for the statistical difference between facies. For example, the parent water

233 in experiment 1 had a lighter $\delta^{18} \mathrm{O}$ value (-7.7\%o) compared to experiment $3(-6.1 \%$ ).

234 Consequently, the facies which formed in these individual experiments had contrasting compositions in their $\delta^{18} \mathrm{O}$ values. 


\subsubsection{Deuterium Excess}

237 Across the four experiments, the herringbone ice had the heaviest deuterium excess

238 values compared to the other facies and the clear ice had lightest values (Figure 5). The

239 mixed facies plotted between the clear and herringbone facies in each experiment when

240 placed on deuterium excess- $\delta \mathrm{D}$ diagrams.

241 [Figure 5 near here]

\subsection{Freezing Slopes}

243 The freezing slopes were not predicted by the Jouzel and Souchez (1982) closed-system

244 model. For example, experiment 3 had a freezing slope of 5.95, yet a slope of 7.74 was

245 predicted (Table 2). The freezing slopes had high adjusted $\mathrm{R}^{2}$ values, ranging from 0.93

246 (experiment 3) to 0.99 (experiment 1 and 2), suggesting the slopes are a good fit for our

247 data across all the experiments.

248 [Table 2 near here]

\section{$249 \quad 3.4$ Analysis of Variance Testing}

250 Analysis of variance (ANOVA) testing determines the statistical difference between individual parameters. A one-way ANOVA test was conducted for the four experiments to determine whether the documented facies were significantly different isotopically.

253 After analysis and Tukey's post-hoc comparisons of the facies' mean value, the isotopic

254 compositions of the documented facies in in all four experiments were statistically

255 different from each other ( $\mathrm{p}$ values $<0.005$ ), and we can assert with $95 \%$ confidence

256 that the clear, herringbone and mixed facies are significantly different (Table 3).

$257 \quad$ [Table 3 near here] 


\subsection{Discussion}

\subsection{Implications for Glaciohydraulic Supercooling Studies}

260 Our results suggest that bulk-scale sampling of ice facies frozen from supercooled water

261 could be overlooking micro-scale isotopic differences. This is evident as the

262 herringbone facies is significantly isotopically distinct from the mixed facies $(95 \%$

263 confidence $-\mathrm{p}$ values $<0.005)$. Consequently, previous studies investigating

264 glaciohydraulic supercooling which bulk sampled basal ice facies may have lacked

265 methodological precision (e.g. Titus et al. 1999; Ensminger et al. 2001; Swift et al.

266 2006; Cook et al. 2010; Larson et al. 2010). It remains unclear whether bulk-scale

267 samples are isotopically distinct when compared to micro-scale samples in field-based

268 investigations. Had the mixed facies containing both the clear and herringbone crystal

269 structures been sampled to determine the isotopic signature of the herringbone facies,

270 the isotopic resolution would have been lost. This is shown through the mean isotopic

271 differences between the mixed and herringbone facies which were $-12.2 \%$ to $-14.6 \%$ o

272 for $\delta \mathrm{D}$ and -1.9 to $-2.3 \%$ for $\delta^{18} \mathrm{O}$ (Table 3 ). This indicates that a micro-scale sampling

273 approach has yielded a more accurate isotopic signature for the facies formed from

274 supercooled water, rather than a bulk-scale sampling approach containing numerous

275 facies.

Ice frozen from supercooled water at glaciers has been shown to be isotopically

277 lighter relative to the vent water (Lawson et al. 1998; Ensminger et al. 2001; Cook et al.

278 2010; Larson et al. 2010). However, in our experiments the herringbone facies frozen

279 from supercooled water was isotopically heavier relative to the initial reservoir and

280 surrounding facies (Figure 4). These results are not the norm with regards to isotopic

281 enrichment seen in stratified basal ice facies, anchor and frazil ice produced by

282 supercooling. In our experiments, the clear ice formed at the beginning of the system, 
whereas the herringbone ice formed during the latter stages. Souchez and Jouzel (1984)

284 assert that ice which forms at the beginning of a system will be isotopically lighter, whereas ice which forms last will be isotopically heavier, relative to the initial water.

286 Experiment 1 had a freezing slope of 7.23 , yet the clear facies had a slope of 6.33 , the

287 herringbone facies a slope of 6.15 and the mixed ice 3.96. Souchez and De Groote

288 (1985) stated ice facies that form in a closed-system should have similar slopes to that

289 of the system because there is no mixing of external water sources. Despite the closed-

290 system experiments here, the facies have contrasting slopes. This could be because the

291 initial reservoir became isotopically heavier throughout the seven-day period and the

292 facies which froze at different periods of the experiments had different slopes. As the

293 clear facies formed at the start of the experiment when the initial reservoir was

294 relatively isotopically light. The herringbone facies formed in the latter stages of the experiment when the water was isotopically heavier, compared to the water that formed the clear ice at the start of the experiment. Thus, the isotopically heavy nature of the herringbone ice can be explained by a Rayleigh fractionation process. Despite the facies frozen from supercooled water not experiencing similar isotopic enrichment as seen in

299 field-based investigations, our results confirm the importance of sampling size in correctly distinguishing the facies diagnostic of supercooling. containing two separate crystal structures with contrasting isotopic compositions. We

303 suggest the mixed ice isotopic composition is being amalgamated because of the light

304 isotopic composition of the clear ice and the heavy isotopic composition from the 305 herringbone ice. This emphasises the need for a micro-scale sampling approach and 306 removal of alternate ice facies in a believed 'supercooled' sample. Consequently, the 307 assertions of Cook et al. (2010) that sample sizes of basal ice will be important for 
308 isotopic analysis as bulk-scale sampling could be homogenising isotopic signatures are

309 correct in the case of this study.

310 Despite the aim of our study being to determine the potential difference between

311 the mixed and herringbone ice facies, it is also important to note that there is a

312 significant statistical difference between the clear and mixed facies. This suggests that

313 the mixed facies cannot distinguish a precise isotopic composition for both the clear and

314 herringbone facies, instead exhibiting a distinct isotopic signature. This supports the

315 concept that bulk-scale sampling techniques could be amalgamating isotopic

316 compositions from contrasting facies and a micro-scale approach is worth considering

317 to ensure more precise measurements.

\section{$318 \quad 4.2$ Isotopic Analysis}

319 Our results indicate that the closed-system model by Jouzel and Souchez (1982) did not

320 align with the actual freezing slopes of our experiments (Table 3), suggesting a complex

321 freezing system. Had the model determined the correct freezing slope, it would have

322 suggested the water froze from simple freezing. Sharp et al. (1994) found basal ice

323 facies at Variegated Glacier, Alaska had formed from a different water source or the

324 stratified facies had been subject to modification post-formation. This was concluded

325 because the closed-system model calculated slopes of 6.37 and 6.64 for two initial

326 liquids, which did not correlate with the actual slope of 5.77 (Sharp et al. 1994).

327 Fitzsimons et al. (2008) determined an overriding apron at the Victoria Upper Glacier,

328 Antarctica did not form the basal ice because it was isotopically distinct, with a

329 predicted freezing slope of 5.6 which was not significantly similar to the actual slope of

330 6.6. Gordon et al. (1988) found the actual freezing slope at Flute's Glacier, Norway had

331 a gradient of 5.5 which was in close agreement with the closed-system model which

332 calculated a slope of 5.7, therefore basal ice formed from a melting-refreezing process. 


\subsubsection{Initial Water Differences}

The Jouzel and Souchez (1982) model and the coefficients by Lehmann and Siegenthaler (1991) were formulated based upon meteoric water, yet our study utilised tap water. This mismatch in parent water could be the controlling parameter for the failure of the models predicting the freezing slopes of the experiments. For example, the isotopic composition of the tap water varied throughout the experimental period, resulting in different experiments having different parent waters. Experiment 1's parent water had an isotopic composition of $-49.87 \%$ for $\delta \mathrm{D}$ and $-7.674 \%$ for $\delta^{18} \mathrm{O}$, whereas experiment 4's composition was $-50.12 \%$ for $\delta \mathrm{D}$ and $-6.060 \%$ for $\delta^{18} \mathrm{O}$. If the models cannot be applied to a tap water source, other explanations of a complex freezing system will be of secondary importance. This has presented a potential avenue for further work to determine whether Jouzel and Souchez (1982) closed-system model can be applicable for different water sources, other than meteoric.

\subsubsection{Potential Kinetic Isotope Effects}

The deuterium excess- $\delta \mathrm{D}$ diagram (Figure 5) demonstrates the facies isotopic values tend to become heavier with progressive freezing through the closed-system. Souchez et al. (2000) found $\delta$-values decreased towards the base of the ice cover, suggesting the downward movement of a freezing front. Our results indicate similar findings as our system froze progressively downwards and consequently resulted in the heaviest deuterium excess values contained in the herringbone facies as it was the last to freeze. Yde et al. (2010) studied basal ice facies at Russell Glacier and found that apart from the white ice, the other ice types had deuterium excess values between 2.0 and 4.2, suggesting there was no evident correlation with $\delta \mathrm{D}$. It was inferred that the basal ice facies had been affected by; 1) kinetic parameters; 2) the local meteoric water had an average deuterium excess value within the range; 3) partial freezing or 4) variations in 
parent waters (Yde et al. 2010). Our results do see an inverse fractionation process. This

359 occurs when the isotopes which are substituted are stably bonded during the transitional

360 period and the molecules containing the heavy isotopes react quickly (Casciotti, 2009).

361 Our experimental method could have caused the water isotopes in the facies to be stably

362 bonded during transitional and progressive freezing of a downward front, resulting in an

363 inverse fractionation process.

\section{$364 \quad 4.3$ Basal Ice Context}

365 We are aware that our experiments are laboratory based and do not perfectly replicate

366 real-world conditions. However, our results highlight the importance of the scale of

367 sample of basal ice collected for isotopic analysis. There have long been questions

368 regarding the importance of sample sizes of basal ice for isotopic analysis (Souchez et

369 al. 1998; Hubbard and Sharp. 1993; Cook et al. 2010). Hubbard and Sharp (1993)

370 demonstrated that a bulk-scale sampling approach could incorporate different laminae

371 of facies and may not allow a high enough resolution for a particular basal ice layer

372 which has formed from a singular freezing event. Consequently, the overall benefit of a

373 high-resolution sampling approach is more accurate isotopic signatures of basal ice

374 layers in question. If a sample amalgamates different facies formed from different initial

375 waters and formational processes, the isotopic resolution of the wanted basal ice layer

376 will be lost, as presented here. If the mixed facies in our experiments were used as the

377 only proxy for a supercooled formation, the diagnosis would have been misleading and

378 fundamentally inaccurate. This theory could be applied to basal ice studies in general

379 because of the complexities of stable water isotope analysis at glaciers. We have

380 provided a proof of concept experiment for all basal ice investigations to consider the

381 scale of samples for isotopic analysis. Further work is needed in basal investigations at 
382 glaciers to determine whether our theory is correct and will hopefully develop our

383 understanding of sample size resolution in the real-world.

\section{$384 \quad 5.0$ Conclusions}

385 We have four overarching conclusions; model of Jouzel and Souchez (1982). We conclude that this was due to two factors; 1)

404 the system underwent a complex freezing process over the seven-day experiment and 2) the use of tap water rather than meteoric water as the parent water source. 
407 We thank Louis Howell (PhD candidate at Keele University) for his comments on 408 earlier versions of this manuscript. We thank the associate editor Darrel Swift, Jacob

409 Yde and an anonymous reviewer for their comments which have vastly improved the 410 manuscript.

\section{Declaration of interest statement}

412 In accordance with Taylor \& Francis policy and our ethical obligation as researchers,

413 we report having received no funding and declare that none of the authors have a

414 conflict of interest.

\section{Notes on contributors}

416 Connor Shiggins is a PhD student at the University of Liverpool, with a project directed

417 towards investigating and modelling calving events at marine-terminating glaciers in

418 Greenland. The research presented in this manuscript was conducted during his MSc

419 degree at Keele University.

420 Matthew Harris is a PhD student at Keele University using fluorescence spectroscopy

421 and stable water isotopes to reconstruct climate and ocean dynamics preserved in

422 Antarctic ice cores.

423 Peter Knight is a Reader in Geography at Keele University. His research focus is on 424 basal ice investigations.

425 Chris Fogwill is a Professor of Glaciology and Palaeoclimatology at Keele University.

426 His main research interests are past and future climate changes in Antarctica and the

427 Southern Ocean. 


\section{References}

431 Alley RB, Lawson DE, Evenson EB, Strasser JC, Larson GJ. 1998. Glaciohydraulic

432 supercooling: a freeze-on mechanism to create stratified, debris-rich basal ice: II.

433 Theory. Journal of Glaciology. 44(148):563-569.

434 Casciotti KL. 2009. Inverse kinetic isotope fractionation during bacterial nitrite oxidation. Geochimica et Cosmochimica Acta. 73.(7):2061-2076.

436 Cook SJ, Knight PG, Knight DA, Waller RI. 2012. Laboratory observations of sediment 437 entrainment by freezing supercooled water. Geografiska Annaler: Series A, Physical $438 \quad$ Geography. 94(3):351-362.

439 Cook SJ, Knight PG, Waller RI, Robinson ZP, Adam WG. 2007. The geography of

440 basal ice and its relationship to glaciohydraulic supercooling: Svínafellsjökull, 441 southeast Iceland. Quaternary Science Reviews. 26(19):2309-2315.

442 Cook SJ, Robinson ZP, Fairchild IJ, Knight PG, Waller RI, Boomer IAN. 2010. Role of 443 glaciohydraulic supercooling in the formation of stratified facies basal ice:

444 Svínafellsjökull and Skaftafellsjökull, southeast Iceland. Boreas. 39(1):24-38.

445 Craig H. 1961. Isotopic variations in meteoric waters. Science. 133(3465):1702-1703.

446 Ensminger SL, Alley RB, Evenson EB, Lawson DE, Larson GJ. 2001. Basal-crevasse-

447 fill origin of laminated debris bands at Matanuska Glacier, Alaska, USA. Journal of $448 \quad$ Glaciology. 47(158):412-422.

449 Evenson EB, Lawson DE, Strasser JC, Larson GJ, Alley RB, Ensminger SL, Stevenson 450 WE. 1999. Field evidence for the recognition of glaciohydraulic supercooling, in: 
Fitzsimons S, Webb N, Mager S, MacDonell, S, Lorrain R, Samyn D. 2008. entrainment model. Journal of Geophysical Research: Earth Surface. 113(2).

Gordon JE, Darlinc WG, Whalley WB, Gellatly AF. $1988 \delta \mathrm{D}-\delta 180$ relationships and the thermal history of basal ice near the margins of two glaciers in Lyngen, North Norway. Journal of Glaciology. 34(118):265-268.

Hubbard B, Sharp M. 1993. Weertman regelation, multiple refreezing events and the isotopic evolution of the basal ice layer. Journal of Glaciology, 39(132):275-291.

Jouzel J, Souchez RA. 1982. Melting-refreezing at the glacier sole and the isotopic composition of the ice. Journal of Glaciology. 28(98):35-42.

Knight PG, Knight DA. 2005. Laboratory observations of debris-bearing ice facies frozen from supercooled water. Journal of Glaciology. 51(173):337-339.

Knight PG, Knight DA. 2006. Laboratory observations of ice formation and debris entrainment by freezing turbid supercooled water, in: Glacier science and environmental change, edited by Knight, P.G., Blackwell Publishing, Oxford UK. p. 456-458. Iceland. Boreas. 39(3):457-470. 
472 Larson GJ, Menzies J, Lawson DE, Evenson EB, Hopkins NR. 2016. Macro-and micro-

473 sedimentology of a modern melt-out till-Matanuska Glacier, Alaska,

$474 \quad$ USA. Boreas. 45(2):235-251.

475 Lawson DE, Strasser JC, Evenson EB, Alley RB, Larson GJ, Arcone SA. 1998.

476 Glaciohydraulic supercooling: a freeze-on mechanism to create stratified, debris-rich

477 basal ice: I. Field evidence. Journal of Glaciology. 44(148):547-562.

478 Lehmann MASU, Siegenthaler U. 1991. Equilibrium oxygen-and hydrogen-isotope 479 fractionation between ice and water. Journal of Glaciology. 37(125):23-26.

480 Lorrain RD, Fitzsimons SJ, Vandergoes MJ, Stievenard M. 1999. Ice composition 481 evidence for the formation of basal ice from lake water beneath a cold-based $482 \quad$ Antarctic glacier. Annals of Glaciology. 28:277-281.

483 Roberts MJ, Tweed FS, Russell AJ, Knudsen Ó, Lawson DE, Larson GJ, Evenson EB, 484 Björnsson H. 2002. Glaciohydraulic supercooling in Iceland. Geology. 30(5):439485442.

486 Sharp M, Jouzel J, Hubbard B, Lawson W. 1994. The character, structure and origin of 487 the basal ice layer of a surge-type glacier. Journal of Glaciology. 40(135):327-340.

488 Souchez RA, De Groote JM. 1985. $\delta$ D- $\delta 180$ relationships in ice formed by subglacial 489 freezing: Paleoclimatic implications. Journal of Glaciology. 31(109):229-232.

490 Souchez RA, Jouzel J. 1984. On the isotopic composition in $\delta \mathrm{D}$ and $\delta 180$ of water and 491 ice during freezing. Journal of Glaciology. 30(106):369-372. 
Souchez R, Jouzel J, Lorrain R, Sleewaegen S, Stiévenard M, Verbeke V. 2000. A

493 kinetic isotope effect during ice formation by water freezing. Geophysical Research $494 \quad$ Letters, 27(13):1923-1926

495 Souchez R, Lorrain R, Tison JL, Jouzel J. 1988. Co-isotopic signature of two 496 mechanisms of basal-ice formation in Arctic outlet glaciers. Annals of Glaciology. $497 \quad 10: 163-166$.

498 Spedding N, Evans DJ. 2002. Sediments and landforms at Kviárjökull, southeast 499 Iceland: a reappraisal of the glaciated valley landsystem. Sedimentary $500 \quad$ Geology. 149(1-3):21-42.

501 Swift DA, Cook SJ, Graham DJ, Midgley NG, Fallick AE, Storrar R, Rodrigo MT, 502 Evans DJA. 2018. Terminal zone glacial sediment transfer at a temperate 503 overdeepened glacier system. Quaternary Science Reviews. 180:111-131.

504 Swift DA, Evans DJ, Fallick AE. 2006. Transverse englacial debris-rich ice bands at 505 Kvíárjökull, southeast Iceland. Quaternary Science Reviews. 25(13-14):1708-1718.

506 Titus DD, Larson GJ, Strasser JC, Lawson DE, Evenson EB, Alley RB. 1999. Isotopic 507 composition of vent discharge from the Matanuska Glacier, Alaska: implications for 508 the origin of basal ice, in: Glacial processes past and present, Geological Society of 509 America Special Paper 337, edited by Mickelson, D.M. and Attig, J.W., Colorado, $510 \quad$ US. p. $37-44$.

511 Yde JC, Finster KW, Raiswell R, Steffensen JP, Heinemeier J, Olsen J, Gunnlaugsson 512 HP, Nielsen OB. 2010. Basal ice microbiology at the margin of the Greenland ice 513 sheet. Annals of Glaciology, 51(56):71-79. 


\section{Appendices}

515 A1. Isotopic compositions of the ice facies presented in this study.

\begin{tabular}{|c|c|c|}
\hline Sample & $\delta \mathrm{D}(\%)$ & $\delta^{18} \mathrm{O}(\%)$ \\
\hline Parent (experiment 1) & -49.87 & -7.67 \\
\hline Parent (experiment 2) & -50.31 & -7.44 \\
\hline Parent (experiment 3) & -50.12 & -6.06 \\
\hline Parent (experiment 4) & -49.75 & -6.06 \\
\hline \multicolumn{3}{|c|}{ Experiment 1} \\
\hline Herringbone & -81.79 & -12.21 \\
\hline Herringbone & -77.63 & -11.51 \\
\hline Herringbone & -75.72 & -11.31 \\
\hline Herringbone & -77.46 & -11.21 \\
\hline Herringbone & -71.62 & -10.67 \\
\hline Herringbone & -75.96 & -11.22 \\
\hline Herringbone & -70.74 & -10.34 \\
\hline Mixed & -60.50 & -8.76 \\
\hline Mixed & -59.64 & -8.66 \\
\hline Mixed & -63.97 & -9.45 \\
\hline Mixed & -61.44 & -9.53 \\
\hline Mixed & -63.23 & -9.66 \\
\hline Mixed & -65.84 & -10.24 \\
\hline Mixed & -59.01 & -9.00 \\
\hline Clear & -44.15 & -6.92 \\
\hline Clear & -44.01 & -6.73 \\
\hline Clear & -39.64 & -6.52 \\
\hline Clear & -37.51 & -5.85 \\
\hline Clear & -43.50 & -6.74 \\
\hline Clear & -48.27 & -7.59 \\
\hline Clear & -44.67 & -7.01 \\
\hline
\end{tabular}




\begin{tabular}{|c|c|c|}
\hline \multicolumn{3}{|c|}{ Experiment 2} \\
\hline Herringbone & -73.34 & -10.89 \\
\hline Herringbone & -67.81 & -9.95 \\
\hline Herringbone & -80.95 & -11.92 \\
\hline Herringbone & -84.15 & -12.42 \\
\hline Herringbone & -87.71 & -12.82 \\
\hline Herringbone & -73.79 & -10.80 \\
\hline Herringbone & -76.76 & -11.23 \\
\hline Mixed & -70.06 & -10.17 \\
\hline Mixed & -56.31 & -8.16 \\
\hline Mixed & -60.53 & -8.75 \\
\hline Mixed & -63.90 & -9.16 \\
\hline Mixed & -67.70 & -9.74 \\
\hline Mixed & -73.37 & -10.40 \\
\hline Mixed & -67.71 & -9.63 \\
\hline Clear & -44.19 & -6.32 \\
\hline Clear & -35.99 & -5.27 \\
\hline Clear & -33.09 & -4.83 \\
\hline Clear & -46.38 & -7.34 \\
\hline Clear & -33.44 & -5.46 \\
\hline Clear & -32.58 & -5.39 \\
\hline Clear & -46.28 & -7.28 \\
\hline \multicolumn{3}{|c|}{ Experiment 3} \\
\hline Herringbone & -77.67 & -10.96 \\
\hline Herringbone & -68.54 & -10.27 \\
\hline Herringbone & -68.88 & -9.63 \\
\hline Herringbone & -80.42 & -11.67 \\
\hline Herringbone & -86.48 & -12.67 \\
\hline Herringbone & -72.04 & -11.00 \\
\hline
\end{tabular}




\begin{tabular}{|c|c|c|}
\hline Herringbone & -78.05 & -11.54 \\
\hline Mixed & -65.10 & -9.63 \\
\hline Mixed & -60.21 & -7.77 \\
\hline Mixed & -58.48 & -8.20 \\
\hline Mixed & -59.34 & -8.93 \\
\hline Mixed & -67.11 & -9.84 \\
\hline Mixed & -57.60 & -7.81 \\
\hline Mixed & -62.37 & -9.41 \\
\hline Clear & -54.31 & -6.94 \\
\hline Clear & -55.40 & -8.16 \\
\hline Clear & -55.74 & -8.02 \\
\hline Clear & -46.20 & -5.49 \\
\hline Clear & -41.86 & -5.53 \\
\hline Clear & -40.04 & -6.39 \\
\hline Clear & -43.17 & -6.77 \\
\hline \multicolumn{3}{|c|}{ Experiment 4} \\
\hline Herringbone & -71.70 & -9.84 \\
\hline Herringbone & -83.91 & -13.52 \\
\hline Herringbone & -71.93 & -10.86 \\
\hline Herringbone & -62.32 & -10.00 \\
\hline Herringbone & -84.37 & -12.95 \\
\hline Herringbone & -73.40 & -11.96 \\
\hline Herringbone & -84.64 & -13.66 \\
\hline Mixed & -62.81 & -10.43 \\
\hline Mixed & -63.37 & -10.53 \\
\hline Mixed & -68.09 & -10.13 \\
\hline Mixed & -61.89 & -9.07 \\
\hline Mixed & -67.26 & -9.70 \\
\hline Mixed & -60.48 & -8.15 \\
\hline
\end{tabular}




\begin{tabular}{|c|c|c|}
\hline Mixed & -62.97 & -8.59 \\
\hline Clear & -34.32 & -4.04 \\
\hline Clear & -39.42 & -4.44 \\
\hline Clear & -37.21 & -3.78 \\
\hline Clear & -34.74 & -3.41 \\
\hline Clear & -37.35 & -3.46 \\
\hline Clear & -43.72 & -6.04 \\
\hline Clear & -43.30 & -6.01 \\
\hline
\end{tabular}

